\title{
Coming Soon To Your Department: Institutional Effectiveness Plans
}

\author{
Kevin J. Lasher and Kenneth Kitts, Francis Marion University
}

Institutional effectiveness came to Francis Marion University with a vengeance in late $1995 .^{1}$ Known informally as "IE," institutional effectiveness refers to a formal system in which a university establishes specific goals, determines how well these goals are achieved, and uses assessment results to improve educational programs.

Three factors combined to make institutional effectiveness a top priority at Francis Marion. First, and most important, the university was scheduled to undergo its reaccreditation visit by the Southern Association of Colleges and Schools (SACS) in March 1997. Second, in its 1996 legislative session, the South Carolina General Assembly had enacted a revolutionary "performance-based" funding model which held public institutions to high standards of results-based accountability. Student retention, graduation rates, and the scholarly output of faculty members were all soon receiving unprecedented attention. Finally, a new administrative team took the helm of the University in 1994. These officials embraced the corporate model of higher education administration and made it known that a push for "continuous improvement" would guide their decision-making process.

This is the story of how our department responded to the administrative charge to develop and implement an institutional effectiveness system for the political science major. Our department chair asked us to serve, along with one full professor, as program effectiveness coordinators (PECs) in September 1996. We inherited a rudimentary IE system which had been created by the outgoing department chair. None of us had any prior experience with this type of endeavor. Thus, we were surprised to learn that a lively cottage industry has sprung up around IE efforts. Most institutions of higher education, from the largest research university to the smallest community college, now employ full-time IE directors. In addition, paid consult- ants earn a handsome living acting as troubleshooters for schools looking to jumpstart their effectiveness efforts.

At this point, a word of warning is in order. Most regional accrediting bodies mandate that the faculty must play a central role in developing program effectiveness plans. ${ }^{2}$ This means that, while IE experts can provide some general direction, the labor-intensive business of develop-

\section{The cornerstone of IE is clarity of purpose, the setting of goals for the}

\section{program.}

ing effectiveness reports is necessarily borne by faculty members. Newcomers should also be aware that the field of IE is still developing its own identity. The experts don't always agree on the fundamentals of their own business. Some of the outside consultants who visited our campus in Fall 1996 offered advice which, at times, contradicted that given by our in-house expert.

\section{Creating the IE Plan}

Our plan began to take shape during Fall $1996 .^{3}$ Reduced to its most basic form, institutional effectiveness contains three key components - goals, assessment, and change. ${ }^{4}$

The cornerstone of IE is clarity of purpose, the setting of goals for the program. Goals are statements that establish expectations for student outcomes and faculty performance. In crafting these goals, we looked to the university's mission statement in order to determine how our program "fit" with the institution's purpose.

Assessment focuses on the effectiveness of the program. Is performance in line with expectations? How well are the goals being met?
To be most useful, the answers to these questions should be reported in measurable terms. Change refers to those modifications which flow from the assessment results. Some of these modifications may simply involve altering the goals or the mechanisms of assessment. Others are more substantive, and could include changes in curriculum, course requirements, methods of instruction, or other aspects of faculty activity.

In the end, goals, assessment, and change all come together in the search for greater institutional effectiveness. After much trial and error, we ultimately settled on an IE plan which revolves around five key program goals.

Goal 1: Graduates will be able to demonstrate an understanding of the core terms, concepts, and principles of political science.

This goal focuses on "what the students have learned" after four years as political science majors. We created two measures for evaluating our progress toward achieving this first goal. The first measure is based on the Area Concentration Achievement Test (ACAT), a standardized external exam. We expect the average score of our graduating political science majors on the ACAT will be at the fiftieth percentile or better. The second measure is based on an internal exam created by the political science faculty. We expect that graduating majors will average eighty percent correct or better on this internal exam.

Our students did not meet the expectation for ACAT performance during the first three semesters in which the exam was administered. The internal exam has now been finalized and will be administered for the first time in the 1997-1998 academic year.

Changes were made in the political science curriculum following the first round of assessment. The department agreed to establish and pursue common objectives for the 
U.S. Government and Introduction to Political Science classes. A new one-hour "baccalaureate seminar" was instituted for the proper administration of the achievement tests; this capstone course was offered for the first time in Fall 1997.

Evaluating our progress toward this goal was problematic. First, there are justifiable questions regarding the validity of the achievement tests. Do these achievement tests actually gauge the "knowledge" acquired by our students? Our department has a very loose structure for political science majors; students are required to take only four courses (U.S. Government, Introduction to Political Science, Methodology, and Political Theory). Thus, students are being tested on material that they may have never encountered during their undergraduate career. The department tried to address this problem by choosing an external exam which emphasized the core courses required of our majors. We employed a similar strategy in creating the internal exam.

Another problem was the administration of the test. Initially, the ACAT was administered in the Methodology course that all seniors are required to take. Students took the achievement test near the end of the semester, after they had completed their major research project. The administration of the exam interfered with the instructor's lecture schedule and proved confusing to the students. Many viewed the exam as something "thrown at them" at the last minute, and, consequently, as something not worth devoting much attention to. The introduction of the new baccalaureate seminar course should resolve this problem by providing a more suitable environment in which to administer the exam.

Goal 2: Graduates will be able to demonstrate a knowledge of, as well as the ability to apply, behavioral research techniques used in the study of political science.

The political science faculty determined that majors should learn to develop and test empirical hypotheses and to use statistical research methods. A sampling of student re- search papers from the Methodology class is used to assess this goal. We created three measures to evaluate these papers. The first measure is a three-point scale for the literature review component of the research paper; the second measure is a seven-point scale for the hypothesis construction and data analysis components of the research paper; and the third measure is a combined tenpoint scale for the overall quality of the research paper. We expected two-thirds of the papers sampled to be superior in quality, receiving a total score of seven or better.

The papers evaluated in Spring 1995 did not reach the expectations set forth in our IE plan. As a result, a number of changes were made in the research project assigned in the Methodology course. These changes included reorganizing the class so that the statistics component came earlier in the semester, requiring students to turn in early drafts of their literature reviews, allowing students to review copies of excellent papers from previous classes, adding additional computer orientations for instruction in SPSS, and providing detailed handouts on using the SPSS statistical software. As a result of these changes, students' papers showed significant improvement in the 1995-96 academic year. The expectations for Goal 2 on all three measures were met for Fall 1996 and Spring 1997.

The availability of data drove the creation of Goal 2. The department had Methodology research papers on file from previous semesters. It was not very difficult to translate the different components of the research paper into workable assessment measures. These measures, in turn, guided our thinking as we developed the goal. While this approach to creating goals may not be ideal, it nonetheless offers a practical solution for faculty who are given the task of creating IE programs on a relatively short notice.

Goal 3: Graduates will demonstrate the ability to express complex theoretical arguments in documented writing.

The political science faculty determined that graduating majors should be able to write clearly and coher- ently, and to present and analyze basic theoretical arguments. Assessment of Goal 3 relies on a sampling of student papers from the Political Theory class. We created three measures for evaluating student progress toward this third goal. The first measure is a five-point scale for the analytic component of the theory paper; the second measure is a five-point scale for the organizational and stylistic components of the theory paper; and the third measure is a combined ten-point scale for the overall quality of the theory paper. As with Goal 2, we expected two-thirds of the papers sampled to be superior in quality, receiving a total score of seven or better.

Our students met the expectation for the analytic component of the paper in academic year 1996-97, but fell short on the other two measures. The instructor of the Political Theory course subsequently made changes in the requirements for the paper in Fall 1997. These changes included requiring students to submit preliminary drafts of their papers, having the instructor give extensive written feedback on the quality of these drafts, and encouraging students to visit the University's Writing Center for additional help and instruction.

The evaluation of papers for Goal 2 and Goal 3 is a time-consuming and difficult process. The evaluators of these papers do not teach either the Methodology or Political Theory courses. Thus, they are dealing with material with which they may be unfamiliar. The alternative would be to ask the instructors of these courses to evaluate the papers which they have assigned and graded. We rejected this idea to ensure maximum objectivity. Ideally, we would like to locate a group of outside evaluators to assist in the process; however, this raises a host of logistical problems which would make the procedure more cumbersome.

Goal 4: The political science faculty will engage in professional development and scholarly research.

With the introduction of Goal 4, the focus of our IE efforts shifts from student outcomes to faculty performance. We created two mea- 
sures for this goal. The first assesses professional development and consists of a scale of the following items: the number of conferences or workshops attended, courses taken, new courses developed, significant revisions of existing courses, and memberships in professional organizations. Points are awarded for each activity. For example, creating a new course is worth three points, attending a conference is worth two points, and belonging to a professional organization is worth one point. We expect that the political science faculty should earn a total score of thirty points or more each year. The second measure assesses scholarly research and consists of a scale of the following items: the number of professional publications, papers delivered at professional meetings, participation as a panel chair or panel discussant at professional meetings, research trips, and scholarly presentation to classes, university clubs, or other organizations. Points are awarded for each activity, with the expectation that the political science faculty will earn a total score of twenty points or more each year.

Results for academic year 1996-97 showed that the political science faculty met and exceeded the expectations for both professional development and research. As a result, we decided to increase expectations for academic year 1997-98.

Goal 5: The political science faculty will engage in service to the university and local community.

Our IE director suggested that we include this goal as a means of focusing attention on the broader activities of the political science faculty. We created one measure for assessing achievement of this goal. The measure consists of a scale including participation on university committees and honor societies; memberships in community civic, political, or service organizations; presentations to local organizations; interactions with local primary and secondary schools; and contacts with local, state, or national media. As with Goal 4, different points are awarded for different activities. Our IE plan sets a benchmark of thirty points or more each year for the political science faculty as a whole.

Results for academic year 1996-97 showed that the political science faculty met and exceeded the expectations set for service. Expectations for performance have been increased for academic year 1997-98. To assist the faculty in meeting the higher standard, the department chair began to work more closely with the University's public relations officers to provide more opportunities for faculty to share their expertise with the local community.

Since Francis Marion is primarily a teaching institution, Goal 4 and Goal 5 deal with activities which are of secondary importance for the political science faculty. Consequently, the scales we developed for evaluating research, scholarship, and service might raise concerns at other institu-

\section{In the end, the department faculty decided that the benefits of relatively simple scales outweighed the costs of insufficient distinction between different levels of research and service activity.}

tions. Is not a publication worth a great deal more than a conference paper? Is it not necessary to distinguish between books, monographs, refereed journal articles, non-refereed journal articles, and book reviews? We considered many of these problems in attempting to develop scales that were comprehensive without being cumbersome. A number of compromises were made along the way. In the end, the department faculty decided that the benefits of relatively simple scales outweighed the costs of insufficient distinction between different levels of research and service activity.

\section{Lessons Learned}

We found the creation of an IE plan to be an intellectually challeng- ing and useful process. We also found it to be extremely frustrating at times. Based on our experience, we have three broad suggestions for others who find themselves charged with a similar undertaking.

Plan now or pay later.

One IE expert suggests that it takes four years to develop and implement a university-wide IE system (Nichols 1991, 24). We were brought in as PECs in Fall 1996 and given eight months to create an effectiveness plan for the political science department. This timetable presented obvious challenges for us. We quickly realized that our department was behind the curve in adapting to the new emphasis on accountability in higher education. In the past, we had satisfied external reviewers by producing in-depth self-studies which focused on resources, personnel, and other structural attributes of our department. We supplemented these studies with bits of data drawn from student exit interviews, alumni surveys, and annual faculty reports. Our regional accrediting body, SACS, had itself given outcomes-based assessment only cursory treatment in past visits. 5

But the criteria for judging institutional and program performance have changed significantly in the past decade. The days of relying on introspective narrative are past. Programs should now have specific, measurable goals in place-well in advance of a reaccreditation visit or other external review-and should be prepared to demonstrate the extent to which the goals are being met.

This point was driven home forcefully to us when the administration asked us to show how our current IE plan related to past assessment activity. There was, in fact, little relationship, because we were creating a new IE system. To be sure, our faculty had endeavored for years to identify problems and strengthen the program. But we could not state categorically that the changes made had flowed from a formalized review process. Thus, we decided to detail what informal assessment had taken place, highlight the newly created IE system and incoming assessment data, and promise to continue to refine the plan.

Although this strategy worked, it 
was clear that additional lead time would have made a huge difference in our workload. It would also have enabled us to present our department's assessment activity in a much more favorable light. "Visiting teams don't want to hear what you are going to do," warned an outside consultant, "they want to hear what you have done."

Realize that the development of an IE system requires coordination and cooperation.

As we labored to construct an IE system for our department, some members of the faculty made it clear that they did not take the process very seriously. Their lack of interest helps explain why the two most junior members of the department were assigned most of the responsibility for this important task.

Institutional effectiveness is not something to be "gotten through" with a minimum of pain, nor will it "go away" when the external review is over. Instead, it requires a commitment from the entire faculty to ensure that assessment activity takes place as scheduled, and that the evaluation of results is accomplished in a timely manner. And that is a job that requires more than writing skills; it requires leadership, experience, and, when all else fails, the judicious use of power in the development of a program effectiveness plan.

In addition to serving as departmental coordinators, we both served on university-wide committees which allowed us to view the IE effort as an integrated whole. Our university IE director was frequently at odds with other administration officials and failed to enforce uniformity among the departmental reports taking shape. He resigned before the process was complete. The administration attempted to "rewrite" the final report of a faculty-staff committee whose job it was to evaluate the IE programs established throughout the university. Finally, an unpleasant amount of scapegoating occurred at the end of our accreditation visit when the visiting team offered an unusually high number of recommendations for change.

There are no magical cures for these problems. Administrative interference and faculty resistance to change are certainly not unique to Francis Marion. Even so, our experience suggests that the impact of these obstacles can be lessened with a little foresight. The development or modification of an effectiveness plan should be preceded by an effort to make sure that all faculty understand precisely what is required and what stakes are involved. Here, the department chair and program effectiveness coordinators can play a key role in aggressively communicating these points. And, to the greatest extent possible, the development of an IE plan should be insulated from university politics by encouraging tenured faculty to assume leadership roles in the process.

Focus on the dividends IE can pay in terms of program improvement.

Initially, there was considerable resistance from everyone in the department-authors included - to the idea of institutional effectiveness. Questions abounded. Would assessment-based activities not take on a life of their own, diverting time and attention away from teaching, research, and service? Could standardized exams and other quantitative measures really assess the quality of our program, given its many intangibles and subtleties? Is it fair to establish benchmarks for faculty performance when funds for supplies and travel are shrinking? And finally, where was the variable of student ability and student effort in all this assessment?

Yet, as time wore on, we began to see the value of setting specific program goals. The process forced us to think about the nature of our classes and the education which we are providing to our students. The results of the standardized achievement exam we administered to seniors, for example, underscored the strengths and weaknesses of our instructional program. Our students posted good scores on the international relations and comparative politics segments of the exam, but underperfomed in other areas. Nowhere was this more evident than in the subfield of public administration. Having identified this hole in our program, we set out to correct the problem. Our own public administration specialist met with the faculty to discuss key terms and concepts that all student majors should know. We formalized this emphasis by adding a public administration objective to the list of common goals we include on the syllabi in our introductory courses.

The faculty also decided to create a new one hour class for graduating seniors. This baccalaureate seminar, originally conceived as simply a means for administering the external and internal exams adopted by the department, soon developed into something quite different. The faculty realized that the new class presented an opportunity to prepare students for life after graduation. Much of the instruction will focus on job search skills and the process of gaining admission to graduate or professional school. This class was offered for the first time in Fall 1997 and is being taught by one of the authors. Here, a "necessary evil" has become an important conclusion to the education of our political science majors.

In short, the development and maintenance of an institutional effectiveness plan is a complicated process. On one hand, it is a burdensome endeavor that will necessarily divert time away from more traditional academic pursuits. On the other hand, it can be an invaluable tool for improving educational programs. Whatever the outcome, the one inescapable truth is that IE has arrived as a force to be reckoned with. The winds of accountability are blowing ever stronger and are gradually reshaping the landscape of higher education. Political science departments everywhere are advised to take notice.

\section{Notes}

1. Francis Marion University in Florence, South Carolina, is a public, liberal arts institution with 3600 students. The political science program features seven full-time faculty members and approximately 185 student majors. The University was fully reaccredited in December 1997.

2. A top official of the Western Association of Schools and Colleges writes that faculty "are to be directly involved in assessment efforts. The Commission... expects that assessment efforts not be handled exclusively by administrators" (Wolff 1990, 405).

3. The IE plan that we ultimately created is more complicated than what we describe in this article. Following the advice of our IE 
director, we established a twelve-step process of goal specification, description of the assessment methods and assessment results, and explanation of the changes made in our program. Our report for academic year 1996-97 is twenty-three pages long and is supplemented by seven appendices. For a copy of the report, contact Kevin Lasher via email at klasher@fmarion.edu.

4. Hockaday and Friga (1989) characterize the process as one of "aim, assessment, and action." See pages $30-31$ of their article for a useful summary of the steps involved in constructing an IE plan.

5. See Rogers (1990) for a discussion of the new emphasis on planning and evaluation.

\section{References}

Hockaday, Jeff, and Jerome Friga. 1989. "Assessment of Institutional Effectiveness: A Practical Model for Small Colleges." Community College Review 17:28-33.

Nichols, James. 1991. A Practitioner's Handbook for Institutional Effectiveness and Student Outcomes Assessment Implementation. New York: Agathon Press.

Rogers, James. 1990. "Assessment in the Southern Commission on Colleges." North Central Association Quarterly 65(2): $397-$ 400.

Wolff, Ralph. 1990. "Assessment in the Western Accrediting Commission for Senior Colleges and Universities." North Central Association Quarterly 65(2): 403-09.

\section{About the Authors}

Kevin J. Lasher is assistant professor of political science at

Francis Marion University. He teaches classes on Russian Politics, Asian Politics, and U.S. Foreign Policy. His research interests are Russian democratization and Asian security issues. Lasher received his $\mathrm{Ph} . \mathrm{D}$. from the University of Georgia.

Kenneth Kitts is assistant professor of political science at Francis Marion University.

He teaches classes on the American Presidency, U.S. Foreign and Defense Policy, and Latin American Politics. His research focuses on the relationship between executive power and national security decision making. Kitts received his Ph.D. from the University of South Carolina. 